\title{
Innate Immunity
}

http://ini.sagepub.com/

The potential role of T-cells and their interaction with antigen-presenting cells in mediating immunosuppression following trauma-hemorrhage

Christian R. Walz, Siegfried Zedler, Christian P. Schneider, Markus Albertsmeier, Florian Loehe, Christiane J. Bruns, Eugen Faist, Irshad $\mathrm{H}$. Chaudry and Martin K. Angele

Innate Immunity 2009 15: 233 originally published online 8 July 2009

DOI: $10.1177 / 1753425909104679$

The online version of this article can be found at:

http://ini.sagepub.com/content/15/4/233

\author{
Published by: \\ (\$) SAGE \\ http://www.sagepublications.com \\ On behalf of: \\ International Endotoxin \& Innate Immunity Society
}

Additional services and information for Innate Immunity can be found at:

Email Alerts: http://ini.sagepub.com/cgi/alerts

Subscriptions: http://ini.sagepub.com/subscriptions

Reprints: http://www.sagepub.com/journalsReprints.nav

Permissions: http://www.sagepub.com/journalsPermissions.nav

Citations: http://ini.sagepub.com/content/15/4/233.refs.html

>> Version of Record - Jul 27, 2009

OnlineFirst Version of Record - Jul 8, 2009

What is This? 


\title{
The potential role of $T$-cells and their interaction with antigen-presenting cells in mediating immunosuppression following trauma-hemorrhage
}

15(4) (2009) 233-241

(C) SAGE Publications 2009 ISSN 1753-4259 (print)

$10.1177 / 1753425909104679$

\author{
Christian R. Walz ${ }^{1}$, Siegfried Zedler ${ }^{1}$, Christian P. Schneider ${ }^{1}$, Markus Albertsmeier ${ }^{1}$, \\ Florian Loehe $^{1}$, Christiane J. Bruns ${ }^{1}$, Eugen Faist ${ }^{1}$, Irshad H. Chaudry ${ }^{2}$, Martin K. Angele ${ }^{1}$ \\ ${ }^{I}$ Department of Surgery, Klinikum Grosshadern, Ludwig Maximilians University, Munich, Germany \\ ${ }^{2}$ Center for Surgical Research and Department of Surgery, University of Alabama at Birmingham, Birmingham, \\ Alabama, USA
}

\begin{abstract}
Objective: Trauma-hemorrhage results in depressed immune responses of antigen-presenting cells (APCs) and T-cells. Recent studies suggest a key role of depressed T-cell derived interferon (IFN)- $\gamma$ in this complex immune cell interaction. The aim of this study was to elucidate further the underlying mechanisms responsible for dysfunctional T-cells and their interaction with APCs following trauma-hemorrhage.

Design: Adult $\mathrm{C} 3 \mathrm{H} / \mathrm{HeN}$ male mice were subjected to trauma-hemorrhage (3-cm midline laparotomy) followed by hemorrhage (blood pressure of $35 \pm 5 \mathrm{mmHg}$ for $90 \mathrm{~min}$ and resuscitation) or sham operation. At $24 \mathrm{~h}$ thereafter, spleens were harvested and T-cells (by Microbeads) and APCs (via adherence) were Isolated. Co-cultures of T-cells and APCs were established for $48 \mathrm{~h}$ and stimulated with concanavalin A and lipopolysaccharide. T-Cell specific cytokines known to affect APC function (i.e. interleukin(IL)-2, IL-4 and granulocyte-macrophage colony-stimulating factor (GM-CSF)) were measured in culture supernatants by Multiplex assay. The expression of MHC class II as well as co-stimulatory surface molecules on T-cells and APCs was determined by flow cytometry.

Results: The release of IL-4 and GM-CSF by T-cells was suppressed following trauma-hemorrhage, irrespective of whether sham or trauma-hemorrhage APCs were present. Antigen-presenting cells from animals subjected to trauma-hemorrhage did not affect $\mathrm{T}$-cell derived cytokine release by sham T-cells. In contrast, T-cells from traumahemorrhage animals depressed MHC class II expression of CD11c(+) cells, irrespective of whether APCs underwent sham or trauma-hemorrhage procedure. Surprisingly, co-stimulatory molecules on APCs (CD80, CD86) were not affected by trauma-hemorrhage.

Conclusions: These results suggest that beside IFN- $\gamma$ other T-cell derived cytokines contribute to immunosuppression following trauma-hemorrhage causing diminished MHC II expression on APCs. Thus, T-cells appear to play an important role in this interaction at the time-point examined. Therapeutic approaches should aim at maintenance of T-cell function and their interaction with APCs to prevent extended immunosuppression following trauma-hemorrhage.
\end{abstract}

Keywords: Antigen-presenting cells, dendritic cells, MHC class II, cytokines, co-stimulatory molecules

\section{INTRODUCTION}

Trauma and severe blood loss are associated with depressed cell-mediated immunity, resulting in an increased susceptibility to infectious and septic complications. ${ }^{1}$
In particular, the interaction between innate (e.g. antigen-presenting cells [APCs]) and adoptive (e.g. T-cells) immunity is thought to play a pivotal role in the induction of an adequate cell-mediated immune response. ${ }^{2,3}$ 
Alterations in the immune response of APCs and T-cells have been demonstrated following trauma and blood loss. In particular, MHC class II expression is suppressed on APCs resulting in decreased antigen presentation capacities following trauma-hemorrhage. ${ }^{4}$ Moreover, the ability of APCs to release cytokines in response to lipopolysaccharide (LPS; i.e. interleukin (IL)-12) is diminished following trauma and blood loss. ${ }^{5}$ Similarly, T-cell derived Th1 cytokine productive capacities (i.e. IL-2, interferon(IFN)- $\gamma$, granulocytemacrophage colony-stimulating factor (GM-CSF)) are suppressed whereas the release of immune-suppressive Th2 cytokines (i.e. IL-4, IL-10, GM-CSF) is increased. ${ }^{6}$ This suppression of T-cell and APC functions persists for up to 7 days following trauma-hemorrhage and is associated with an increased susceptibility to sepsis. ${ }^{7}$

For an adequate immune response, an intact interaction between APCs and T-cells is required. In this respect, APC-derived IL-12 has been shown to activate T-cell responses causing an increased release of IFN- $\gamma$ and IL-2. ${ }^{8}$ Conversely, the synthesis and release of IL-12 is thought to be regulated by T-cell derived IFN- $\gamma$. $^{8}$ In addition, several surface molecules like T-cellreceptor, MHC class II on APCs and corresponding co-stimulatory molecules (i.e. CD4, CD8 and CD28 on T-cells and CD80 [B7-1] and CD86 [B7-2] on APCs) are involved in the complex interaction of APCs and T-cells.

Although many studies have been directed towards investigating the immune cells separately and their interaction following trauma and blood loss, it is not known which immune cell is predominately responsible for immunosuppression under those conditions. Recent data suggest that APCs appear to be involved in initiating immunodysfunction. ${ }^{9}$ Conversely, studies by Walz et al. ${ }^{2}$ indicated that trauma-hemorrhaged APCs did not affect IFN- $\gamma$ release by sham T-cells, while T-cells from trauma-hemorrhaged animals depressed IL-12 release by APCs if analyzed $24 \mathrm{~h}$ after shock. Thus, T-cells might be responsible for prolonged immunosuppression after trauma-hemorrhage. The aim of the present study, therefore, was to investigate T-cell-APC interaction in order to clarify the immunosuppressive effect of T-cells on APCs following trauma-hemorrhage. The results from the present study may further help elucidate the pathophysiological mechanisms of immunosuppression following trauma-hemorrhage, thus allowing development of new targets for specific immunotherapy.

\section{MATERIALS AND METHODS}

\section{Animals}

$\mathrm{C} 3 \mathrm{H} / \mathrm{HeN}$ mice (Charles River, Sulzfeld, Germany) aged 6-8 weeks were used in this study. All procedures were carried out in accordance with the guidelines set forth in the Animal Welfare Act and the Guide for the Care and Use of Laboratory Animals by the National Institutes of Health. The Institutional Animal Care and Use Committee of the Regierung von Oberbayern and the Ludwig-Maximillians-University, Munich, Germany approved this project.

\section{Experimental groups}

Male mice were randomly assigned to sham operation or trauma-hemorrhage ( $n=10$ /group).

\section{Trauma-hemorrhage-procedure and sham operation}

Mice were lightly anesthetized with a mixture of Isoflurane (Forene ${ }^{\circledR}$; Abbott Laboratories, Abbott Park, IL, USA), $\mathrm{N}_{2} \mathrm{O}$ and $\mathrm{O}_{2}$ and then turned into a supine position. A $2.5-\mathrm{cm}$ mid-line laparotomy was performed (i.e. trauma was induced), which then was closed aseptically in two layers using Ethilon 6-0 sutures (Ethicon, Inc., Somerville, NJ, USA). The femoral arteries were aseptically cannulated with polyethylene 10 tubing (Clay-Adams, Parsippany, NJ, USA) using minimal dissection techniques. Blood pressure (BP) was constantly monitored by attaching one of the catheters to a blood pressure analyzer (Digi-Med ${ }^{\mathrm{TM}}$, Louisville, KY, USA). Upon awakening, the animals were bled rapidly through the other catheter to a mean BP of $35 \pm 5 \mathrm{mmHg}$ (BP pre-hemorrhage was $95 \pm 5 \mathrm{mmHg}$ ), which was maintained for $90 \mathrm{~min}$. At the end of that period, the animals were resuscitated intra-arterially with lactated Ringer's solution (4 times the shed blood volume over $30 \mathrm{~min}$ ) to provide adequate fluid resuscitation. Lidocaine was applied to the groin incision sites, the catheters were removed, vessels ligated and groin incisions closed.

Sham-operated animals underwent the same groin dissection, which included ligation of both femoral arteries; however, neither hemorrhage nor fluid resuscitation was carried out. Mortality was not observed in this model of trauma-hemorrhage. The trauma-hemorrhage procedure was carried out at the same time of the day in order to avoid fluctuations of plasma hormone levels due to circadian rhythm.

\section{Cell harvesting procedure}

Animals were sacrificed by an overdose of Isoflurane $\left(\right.$ Forene $^{\circledR}$ ) $24 \mathrm{~h}$ after trauma-hemorrhage or sham operation. The spleens were then removed aseptically and placed in cold and sterile phosphate-buffered-solution (PBS; Merck, Darmstadt, Germany). The spleens were 
dissociated by grinding between two cold and sterile microscope slides, suspended in PBS and centrifuged at $300 \mathrm{~g}$ for $10 \mathrm{~min}$. After resuspension of cellular elements, erythrocytes were lysed hypotonically.

\section{T-Cell separation}

T-Cells were separated by using a 'Pan T-cell Isolation Kit' (Miltenyi Biotec, Bergisch Gladbach, Germany), as described by the manufacturer. This system allows negative selection of T-cells via magnetic labelling of all other immune cells. Non-labelled T-cells remained undetected and were allowed to rinse through the magnetic column. In brief, after a two-step labelling of all non-T-cells (i.e. macrophages, dendritic cells, natural killer cells and B-cells), the suspension was allowed to run through a depletion column (composed of ferromagnetic fibers) inserted within a strong magnetic field. The unlabeled T-cells were eluted by repeated washing of the column within the magnetic field. Following this isolation procedure, T-cell purity was found to be $95 \%$. T-Cell and APC functions were not significantly affected using cell sorting via Microbeads.

\section{Separation of antigen-presenting cells}

Using the remaining cell suspension after T-cell isolation, APCs were separated using their ability to adhere on culture plates. In brief, $1 \times 10^{6}$ cells/well of this cell suspension were incubated for $2 \mathrm{~h}$ in 24-well plastic tissue culture plates. The APCs were allowed to adhere on the plastic surface and the non-adherent cells were removed carefully by washing with warm cell-medium. Approximately 100,000 of adherent cells (APCs) remained in each well.

\section{Cell culture}

In an attempt to establish physiologically relevant co-culture conditions, $0.5 \times 10^{6}$ trauma-hemorrhaged or sham T-cells were added to the adherent APCs from trauma-hemorrhaged or sham animals to achieve a ratio of 5:1. This co-culture system resulted in four study groups: group 1, sham T-cells + sham APCs; group 2, sham T-cells + trauma-hemorrhage APCs; group 3, trauma-hemorrhage T-cells + sham APCs; and group 4, trauma-hemorrhage T-cells + trauma-hemorrhage APCs. As controls, single cultures of T-cells and APCs without co-culturing were established. Co-cultures were incubated in $1 \mathrm{ml}$ of Dulbecco's Modified Eagle Medium (Gibco, Invitrogen Carlsbad, CA, USA) with 10\% inactivated fetal calf serum (FCS; Cambrek, Belgium) and $0.1 \%$ gentamycin (BioWhittaker, Belgium) for $48 \mathrm{~h}$ at $37^{\circ} \mathrm{C}$ and $5 \% \quad \mathrm{CO}_{2}$ and stimulated with $2.5 \mu \mathrm{g} / \mathrm{ml}$ sterile and cell culture tested concanavalin A (ConA; Sigma-Aldrich, Saint Louis, MO, USA) and $1 \mu \mathrm{g} / \mathrm{ml}$ cell culture tested LPS from Escherichia coli O55:B5 $(<3 \%$ protein, TCA extracted; Sigma-Aldrich). In addition, co-cultures without stimulation were established to observe the spontaneous secretion of cytokines by T-cells and APCs. After 48-h incubation, the supernatants were harvested, aliquoted and stored at $-70^{\circ} \mathrm{C}$. In addition, cultivated cells were harvested and investigated via flow cytometry.

\section{Assessment of cytokines}

Interleukin-2, IL-4, IL-10, and GM-CSF were determined in the supernatants with kits from BioRad Laboratories (Hercules, CA, USA) as proposed by the manufacturer. In brief, for multiplex assay, $50 \mu$ l of each sample were allowed to react with the cytokine-specific antibody-conjugated beads in microplate wells. The flow-based Bio-Plex protein array system identifies and quantifies each specific reaction based on bead colors according to the manufacturer's information. The magnitude of the reaction was measured using fluorescently labelled reporter molecules, also specific to each target protein.

\section{Flow cytometry}

In an attempt to characterize T-cells (CD3, CD4, CD8 and CD28) and APCs (CD11b, CD11c, CD80, CD86 and MHC II) following co-culture, four color analyses were performed. For this purpose, the following antibodies were used: $\mathrm{CD} 3 \varepsilon$ FITC (clone 145-2C11; B\&D Pharmingen, San Diego, CA, USA), CD4 ECD (clone RM4-5; Caltag Laboratories, Burlingame, CA, USA), CD8a Tri-Color (clone 5H10; Caltag Laboratories) and CD28 PE (clone 37.51; Beckman Coulter, Fullerton, CA, USA). Antigen-presenting cells were labelled with MHC class II SPRD (clone NIMR-4; Beckman Coulter), CD11b ECD for macrophages (clone M1/70.15; Caltag Laboratories), CD11c PE or Alexa Fluor 488 for dendritic cells (clone N418; Caltag Laboratories), CD80 FITC (clone 16-10A1; B\&D, Pharmingen, San Diego, CA, USA) and CD86 PE (clone GL1; B\&D, Pharmingen).

Flow cytometry was performed using a standard protocol. In brief, after 48-h cell culture, all cells of each well were washed with buffer (PBS plus 1\% BSA), centrifuged at $300 \mathrm{~g}$ for $5 \mathrm{~min}$ and blocked for $10 \mathrm{~min}$ on ice with $2 \mu \mathrm{g}$ Fc-blocking antibody (clone 2.4G2; B\&D Pharmingen) to avoid unspecific binding. After repeated washing and centrifugation at $300 \mathrm{~g}$ for $5 \mathrm{~min}$, the cells were incubated for $15 \mathrm{~min}$ with various combinations of primary antibodies (combinations above) against 
surface markers. Six colors of fluorescence were used: FITC (fluorescein-isothiocyanate), Alexa Fluor 488, R-PE (phycoerythrin), SPRD (phycoerythrin-cyanin 5), Tri-Color (R-phycoerythrin-cyanine 5 tandem) and PE-TR (phycoerythrin-Texas Red) to allow detection of several surface markers in one analysis.

After repeated washing, cells were acquired using a Coulter ${ }^{\circledR}$ EPICS XL flow cytometer and 20,000-30,000 events were collected for analysis. To achieve antibody repletion, preliminary titrations were performed; additionally, isotype controls were created for each surface marker used in this setting. The relative fluorescence intensity of a given sample was calculated by subtracting the signal obtained when cells were incubated with the corresponding isotype control from the signal generated by cells incubated with the test antibody.

\section{Statistical analysis}

The results are presented as mean \pm SEM. One-way ANOVA followed by the Student-Newman-Keul's test or Tukey's test as a post hoc test for multiple comparisons were used to determine the significance of the differences between experimental means. A $P$-value of less than 0.05 was considered to be significant.

\section{RESULTS}

\section{Cytokine release by T-cell/APC co-culture}

In an attempt to characterize T-cell responses within the T-cell/APC co-cultures, both Th1 (IL-2, GM-CSF) and Th2 (IL-4, IL-10, GM-CSF) cytokines were determined.

The release of IL-2 slightly decreased in the presence of hemorrhaged T-cells or APCs cultured with sham APCs (group 2) or T-cells (group 3) when compared to group 1 (sham T-cells and sham APCs; Fig. 1). This decline, however, was not significant. Only group 4 (co-cultured hemorrhaged T-cells and APCs) displayed significantly suppressed IL-2 release capacities.

The production of GM-CSF (Fig. 2) by sham T-cells was similar, irrespective of whether co-cultured APCs were harvested from sham (group 1) or trauma-hemorrhaged animals (group 2). Trauma-hemorrhaged T-cells co-cultured with sham or trauma-hemorrhaged APCs displayed significantly depressed capacity to release GM-CSF.

Likewise, sham T-cells produced similar amounts of IL-4 (Fig. 3) when co-cultured with APCs harvested from sham (group 1) or trauma-hemorrhaged animals (group 2). Trauma-hemorrhaged T-cells showed significantly reduced capacity to release IL-4, irrespective of whether they were co-cultured with sham or traumahemorrhaged APCs.

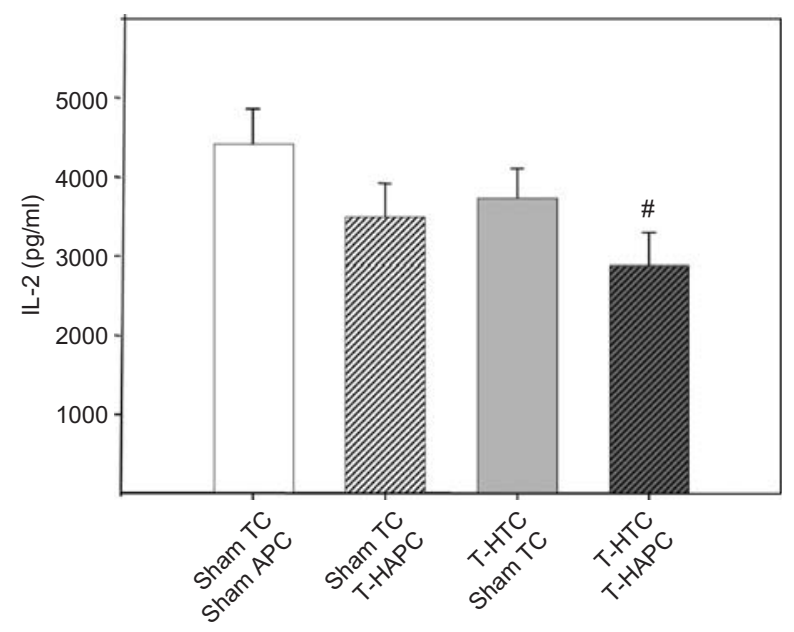

Fig. 1. Co-cultures of T-cells and antigen presenting cells (APCs) harvested $24 \mathrm{~h}$ after sham or trauma-hemorrhage: group 1 , sham $\mathrm{T}$ cells + sham APCs; group 2, sham T cells + trauma-hemorrhage APCs; group 3, trauma-hemorrhage T-cells + sham APCs; and group 4, traumahemorrhage T-cells + trauma-hemorrhage APCs. Co-cultures were stimulated for $48 \mathrm{~h}$ with ConA and LPS. The T-cell-derived cytokine IL-2 was measured in the supernatants by Multiplex assay. $n=8-10$ per group, mean \pm SEM, ANOVA, ${ }^{\#} P<0.05$ versus group 1.

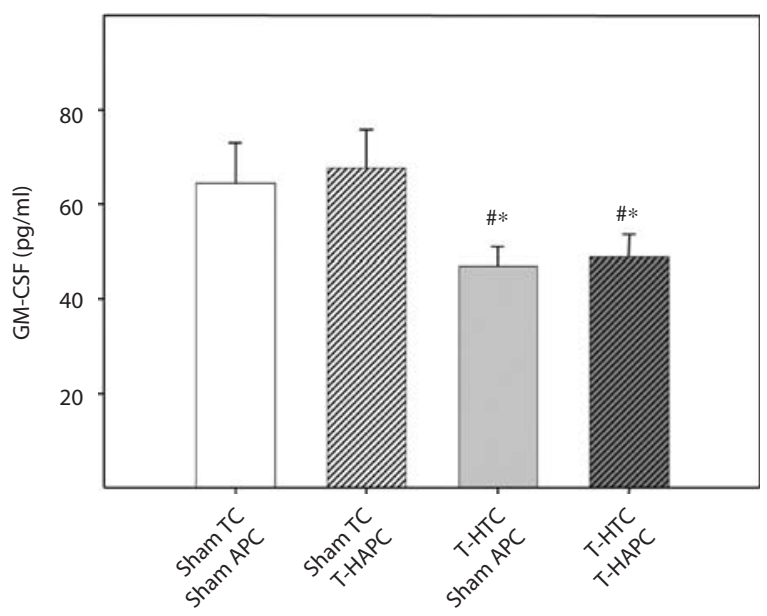

Fig. 2. Co-cultures of T-cells and antigen presenting cells (APCs) harvested $24 \mathrm{~h}$ after sham or trauma-hemorrhage: group 1, sham $\mathrm{T}$ cells + sham APCs; group 2, sham T cells + trauma-hemorrhage APCs; group 3, trauma-hemorrhage T-cells + sham APCs; and group 4, traumahemorrhage T-cells + trauma-hemorrhage APCs. Co-cultures were stimulated for $48 \mathrm{~h}$ with ConA and LPS. The T-cell-derived cytokine GM-CSF was measured in the supernatants by Multiplex assay. $n=8-10$ per group, mean $\pm \mathrm{SEM}$, ANOVA, ${ }^{*} P<0.05$ versus group $1,{ }^{\#} P<0.05$ versus group 2 .

The release of IL-10 was similar in all study groups (Fig. 4). In addition, separate T-cells and APCs were cultured and stimulated with ConA and LPS. Interestingly, T-cells, but not APCs, released IL-10 when incubated separately. The release of separately cultured T-cells was unaffected by trauma-hemorrhage compared to sham operation. 


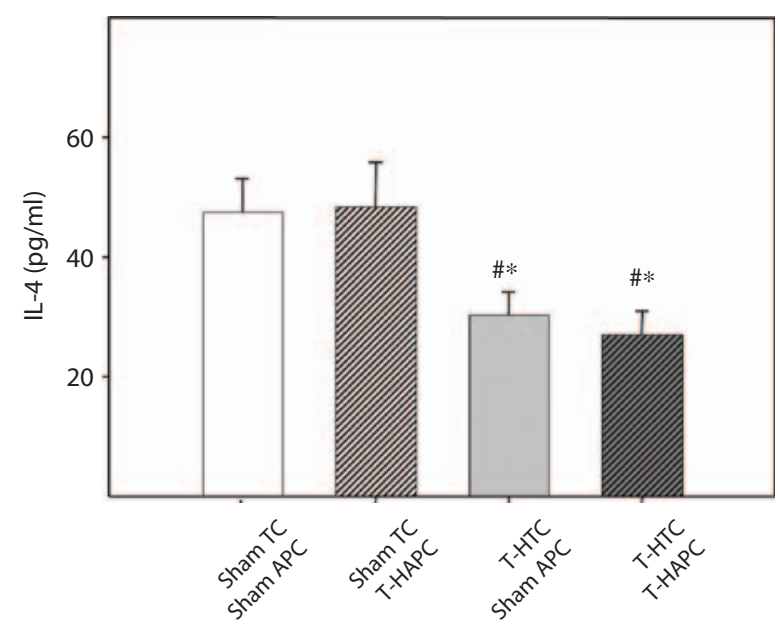

Fig. 3. Co-cultures of T-cells and antigen presenting cells (APCs) harvested $24 \mathrm{~h}$ after sham or trauma-hemorrhage: group 1, sham T-cells + sham APCs; group 2, sham T cells + trauma-hemorrhage APCs; group 3, trauma-hemorrhage T-cells + sham APCs; and group 4, traumahemorrhage T-cells + trauma-hemorrhage APCs. Co-cultures were stimulated for $48 \mathrm{~h}$ with ConA and LPS. The T-cell-derived cytokine IL-4 was measured in the supernatants by Multiplex assay. $n=8-10$ per group, mean $\pm \mathrm{SEM}$, ANOVA, ${ }^{*} P<0.05$ versus group $1,{ }^{\#} P<0.05$ versus group 2 .

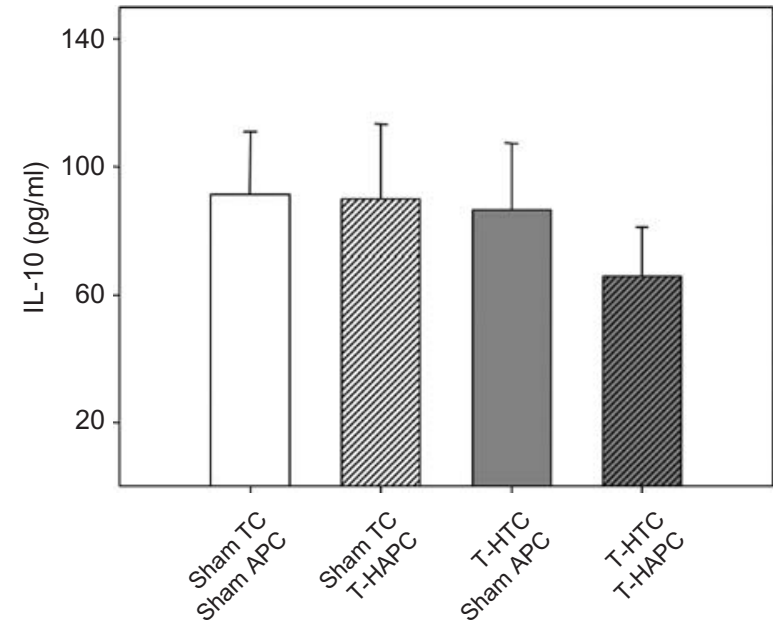

Fig. 4. Co-cultures of T-cells and antigen presenting cells (APCs) harvested $24 \mathrm{~h}$ after sham or trauma-hemorrhage: group 1, sham T-cells + sham APCs; group 2, sham $\mathrm{T}$ cells + trauma-hemorrhage APCs; group 3, trauma-hemorrhage T-cells + sham APCs; and group 4, trauma-hemorrhage T-cells + trauma-hemorrhage APCs. Co-cultures were stimulated for $48 \mathrm{~h}$ with ConA and LPS. The APC-derived cytokine IL-10 was measured in the supernatants by Multiplex assay. $n=8-10$ per group, mean \pm SEM, ANOVA.

\section{Cell-surface molecules}

\section{$\mathrm{CD4}^{+} / \mathrm{CD8}^{+}{ }^{+}$distribution within $\mathrm{T}$-cell population}

The expression of the T-cell-specific surface molecule CD3, phenotypic aspects and the stimulation status were similar in all study groups and, therefore, not altered by trauma-hemorrhage.

The $\mathrm{CD}^{+} / \mathrm{CD}^{+}$ratio of T-cells from hemorrhaged or sham-operated animals was the same, independent of whether they were co-cultured with trauma-hemorrhaged or sham APCs. However, trauma-hemorrhage consistently decreased the $\mathrm{CD} 4^{+} / \mathrm{CD} 8^{+}$ratio on $\mathrm{T}$-cells irrespective of whether they were co-cultured with APCs from both groups (trauma-hemorrhage or sham), although this effect did not reach statistical significance (Table 1).

\section{Co-stimulatory molecules on T-cells and APCs}

Antigen-presenting cell-specific surface markers (i.e. CD80 and CD86), which are involved in the interaction with T-cells, were not affected by trauma-hemorrhage as indicated by comparable expression in all groups (data not shown).

\section{Expression of MHC class II on APCs}

The expression of MHC class II was significantly suppressed in trauma-hemorrhaged and sham CD11c positive cells (dendritic cells) when APCs were co-cultured with trauma-hemorrhaged T-cells compared to group 1 (sham T-cells and sham APCs; Fig. 5). Trauma-hemorrhaged APCs positive for CD11c cocultured with sham T-cells (group 2) also displayed diminished MHC II expression as opposed to sham APCs co-cultured with sham T-cells (group 1). This decrease, however, was not statistically significant $(P>0.05)$ although it appears biologically relevant. Moreover, MHC class II expression of hemorrhaged APCs co-cultured with sham T-cells (group 2) was not significantly different to groups 3 and 4. Interestingly, MHC class II expression on CD11b positive APCs was neither altered by trauma-hemorrhage nor by co-cultured trauma-hemorrhaged T-cells.

\section{DISCUSSION}

Clinical and experimental studies have demonstrated a depression of cell-mediated immune responses following trauma with severe blood loss. In the post-traumatic setting, patients are prone to infectious complications and their mortality is greatly increased. ${ }^{10-12}$ Defective immune responses have been shown for both T-cells and APCs following trauma and severe blood loss. In this regard, T-cells exhibit reduced capacities to proliferate and to release cytokines such as IL-2 and IFN- $\gamma \cdot{ }^{2,13}$ Similar to T-cells, APCs function is also suppressed following trauma-hemorrhage, as indicated by decreased cytokine releases and reduced antigen presentation via diminished MHC II expression. ${ }^{2,4}$ In those studies, however, T-cells and APCs were not separated prior 
Table 1. Percentage of $\mathrm{CD}^{+}$and $\mathrm{CD} 8^{+} \mathrm{T}$-cells $\left(\mathrm{CD} 3^{+}\right)$in the co-culture

\begin{tabular}{lllll}
\hline & $\mathrm{CD}^{+}(\%)$ & $\mathrm{CD}^{+}(\%)$ & $\mathrm{CD}^{+}(\%)$ & $\mathrm{CD} 4 / \mathrm{CD} 8$ \\
\hline Sham T-cells/sham APCs & $64.9 \pm 3.3$ & $50.9 \pm 4.2$ & $15.4 \pm 0.5$ & 3.31 \\
Sham T-cells/trauma-hemorrhage APCs & $62.9 \pm 1.4$ & $49.4 \pm 2.9$ & $14.9 \pm 0.7$ & 3.31 \\
Trauma-hemorrhage T-cells/sham APCs & $60.7 \pm 1.4$ & $45.9 \pm 1.5$ & $17.1 \pm 1.7$ & 2.68 \\
$\begin{array}{l}\text { Trauma-hemorrhage T-cells/ } \\
\quad \text { trauma-hemorrhage APCs }\end{array}$ & $59.3 \pm 1.2$ & $45.2 \pm 1.3$ & $16.3 \pm 1.4$ & 2.72 \\
\hline
\end{tabular}

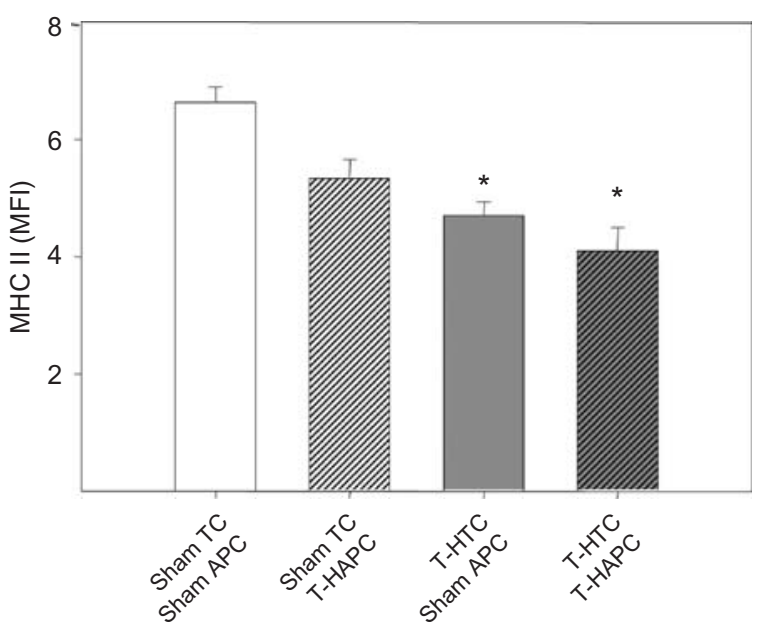

Fig. 5. Expression of MHC class II on $\mathrm{CD} 11 \mathrm{c}(+)$ cells (i.e. dendritic cells) measured by flow cytometry. Group 1, sham T-cells + sham APCs; group 2, sham $\mathrm{T}$ cells + trauma-hemorrhage APCs; group 3, traumahemorrhage T-cells + sham APCs; and group 4, trauma-hemorrhage Tcells + trauma-hemorrhage APCs. Co-cultures were stimulated for $48 \mathrm{~h}$ with ConA and LPS. $n=8-10$ per group, mean \pm SEM, ANOVA, $\mathrm{MFI}=$ mean fluorescence intensity, ANOVA, ${ }^{*} P<0.05$ versus group 1.

to incubation. Thus, it remains unknown whether T-cells and/or APCs are dysfunctional or whether their interaction is primarily affected following traumahemorrhage.

The interaction between APCs and T-cells has been shown to be crucial for an efficient immune response. ${ }^{14}$ In particular, Th1 cytokines (i.e. IFN- $\gamma$, IL-2 by T-cells) and APC-derived cytokines, (i.e. IL-12) play an essential role in this intercellular communication. ${ }^{8}$ Recent studies by Kawasaki et al. ${ }^{9}$ indicated that isolated dendritic cells harvested $2 \mathrm{~h}$ after trauma-hemorrhage caused diminished T-cell responses in vitro. ${ }^{9}$ In contrast, anergic T-cells have been shown to suppress dendritic cell function. ${ }^{15}$ Similarly, recent studies by our group using a co-culture system following immune cell separation demonstrated that trauma-hemorrhaged T-cells are able to depress IL-12 release by APCs. ${ }^{2}$ However, the release of the T-cell cytokine IFN- $\gamma$ remained unaffected by trauma-hemorrhaged APCs. These results suggested that dysfunctional T-cells might be primarily responsible for the persistent immunosuppression observed following trauma-hemorrhage. Therefore, the aim of the present study was to extend those findings by investigating the interaction between T-cells and APCs in vitro in this co-culture system following trauma-hemorrhage or sham operation. The results yield better insight into the pathophysiological mechanism of the cellular immune response following trauma-hemorrhage, which may allow the development of clinically relevant immunomodulatory strategies.

For APC isolation, the ability of antigen-presenting cells to adhere in culture plates was used. ${ }^{16,17}$ Splenic T-cells were isolated by negative selection using magnetic beads resulting in a $95 \%$ purification of T-cells. Since T-cells were not antibody labelled, their cellular function was not altered by the isolation procedure. $^{18}$ B-Cells, NK-cells, gamma delta T-cells, and Treg were not taken into consideration, since the aim of the present study was to elucidate further the interaction between T-cells and APCs. Nonetheless, studies indicate that B-cells, NK-cells, gamma delta T-cells, and Treg might affect T-cell and APC function, ${ }^{19}$ which will be individually isolated via bead selection and their role in affecting APC-T-cell interaction evaluated in future studies.

Co-cultures were incubated in the presence of ConA and LPS as previously described. 2,20,21 This stimulation protocol results in an activation of T-cells and APCs in vitro. ${ }^{22,23}$ Recently, LPS-activated monocytes have been demonstrated to suppress T-cell immune responses. ${ }^{24}$ Thus, studies were conducted using stimulation of co-cultures with ConA or LPS to avoid those interactions.

For a characterization of T-cell and APC function, IFN- $\gamma$ (Th1 cytokine) and IL-12 (released by APCs) have been measured in the co-culture supernatants previously. ${ }^{2}$ The capacity of APCs and T-cells to release cytokines upon in vitro stimulation has been shown to reflect immune cell function. The present work further extends those results by measuring concentrations of an additional Th1 cytokine, IL-2, and the Th2 cytokines IL-4 and IL-10. Additionally, GM-CSF was determined which exhibits Th1 and Th2 characteristics. Co-culturing APCs and T-cells limits the interpretation as to which cell represents the predominant source for the measured cytokine. In this respect, cytokines IL-2, IFN- $\gamma$ and IL- 4 have been shown to be predominately 
released by T-cells. ${ }^{25}$ Further support for this notion comes from the findings of this study, which demonstrated an excessive release of IL-2 and IL-10 by separated T-cells but not APCs (data not shown). Granulocyte-macrophage colony-stimulating factor, however, has been shown to be released by T-cells, macrophages and dendritic cells. ${ }^{26}$

The results of the present study demonstrate diminished IL-4 and GM-CSF release capacities by trauma-hemorrhaged T-cells irrespective of whether trauma-hemorrhage or sham APCs were co-cultured. Those findings are in line with previous results showing reduced IFN- $\gamma$ and IL-12 concentrations in co-cultures with hemorrhaged T-cells and sham or hemorrhaged APCs. ${ }^{2}$ In contrast, the release of the Th1 cytokine IL-2 was only significantly decreased when hemorrhaged T-cells and hemorrhaged APCs were co-cultured, suggesting that some T-cell responses may depend on APC function.

In contrast to previous studies by Ayala et al. ${ }^{27}$ we did not detect enhanced release of the Th2 cytokine IL-10 in our model of trauma-hemorrhage. In those studies, however, non-separated spleen cells were stimulated only with ConA and not with a combination of ConA and LPS which might account for the different results.

With regard to the interaction of T-cells and APCs, studies indicate that APC-derived IL-12 increases the release of Th1 cytokines, whereas the Th1 cytokines IL-2 and IFN- $\gamma$ stimulate the release of IL- $12 .{ }^{28}$ The study by Walz et al. ${ }^{2}$ suggests that the depressed release of IFN- $\gamma$ by trauma-hemorrhaged T-cells is not the result of diminished APC responses. In contrast, depressed APC cytokine secretion in the presence of traumahemorrhaged T-cells indicates that the diminished IFN- $\gamma$ release contributes to a defective APC function. This observation is supported by studies of Asthana et al. ${ }^{29}$ who showed a restoration of the suppressed APC response following trauma-hemorrhage by IFN- $\gamma$ treatment in vivo. Similarly, Ertel et al. ${ }^{8}$ demonstrates salutary effects of IFN- $\gamma$ on the depressed IL-12 release by PBMCs harvested from septic patients. In contrast, studies by Kawasaki et al. ${ }^{9}$ indicate suppressive effects of APCs harvested $2 \mathrm{~h}$ after trauma-hemorrhage on a T-cell line potentially due to depressed IL-12 release capacities. Nonetheless, the findings of the present study together with previous results collectively suggest that depleted APC responses may be crucial for initiating immunosuppression early after trauma-hemorrhage, whereas T-cells predominately contribute to a prolonged immunodepression.

This evolution in the behaviour of APCs after trauma and hemorrhage might reflect a process of maturation of dendritic cells over time following an inflammatory insult. ${ }^{30}$ Differentiation of dendritic cells is, in part, controlled by T-cell-derived cytokines (i.e. IL-4 and GM-CSF). ${ }^{31}$ To what extent the depressed release of IL-4 and GM-CSF by T-cells following trauma-hemorrhage further affects dendritic cell maturation was not examined and was beyond the scope of the present study. Nonetheless, studies have demonstrated that the development of dendritic cells from monocyte precursors is shifted toward macrophage lineage after traumatic injury and that the capacity of dendritic cells to activate and present antigen effectively to T-cells is impaired. ${ }^{32}$ Both pathophysiological mechanisms might contribute to initiate the observed T-cell depression following trauma and hemorrhagic shock.

In an attempt to characterize T-cells (CD4, CD8, and CD28) and APCs (CD80 and CD86) further, surface molecules were measured by flow cytometry. The cell surface molecules CD3, CD4 and CD8 on T-cells were not affected by trauma-hemorrhage in the present study. In contrast, Schneider et al. ${ }^{33}$ demonstrated a suppressed ratio of CD4/CD833 whereas Oberbeck et al. ${ }^{34}$ found an increased ratio. Those T-cells, however, were naive as opposed to stimulated T-cells in the present study. This might account for the divergent results. Furthermore, the co-stimulatory molecules CD28 on T-cells and its ligands on APCs CD80 (B7.1) and CD86 (B7.2) were also not altered $24 \mathrm{~h}$ after trauma-hemorrhage. In this regard, maximum expression has been reported at 6 days after stimulation. ${ }^{35}$ Similarly, Kawasaki et al. ${ }^{9}$ demonstrated unchanged CD80 and CD86 expression on dendritic cells $2 \mathrm{~h}$ after trauma-hemorrhage.

In addition, MHC class II expression on APCs was measured as a functional parameter to quantify the ability of dendritic cells (CD11c positive) and macrophages (CD11b positive) to present foreign antigens. Expression of MHC class II has been shown to correlate with the antigen presentation capacity of APCs. ${ }^{4}$ The results of the present study indicate that MHC class II expression was depressed on trauma-hemorrhaged APCs when co-cultured with trauma-hemorrhaged or sham T-cells. This decrease, however, was only significant in the presence of hemorrhaged T-cells. Interestingly, sham APCs co-cultured with hemorrhaged T-cells also displayed significantly decreased MHC II expression. This suggests that altered T-cell functions following hemorrhage may contribute to diminished MHC expression by APCs. Since MHC class II is regulated, in part, by IFN$\gamma$, which is produced mainly by activated T-cells, differences in MHC class II expression on APCs may be linked to the inability of T-cells to produce adequate amounts of IFN- $\gamma \cdot{ }^{36}$ Further support for this concept comes from our findings that the depressed MHC class II expression on hemorrhaged APCs can be restored, in part, by co-incubation with intact T-cells harvested from sham animals. Those alterations in MHC class II expression on APCs further support the importance of T-cells in the pathophysiological process of 
immunosuppression following trauma-hemorrhage. It should be noted that the depression of MHC II in the present study was restricted to CD11c positive cells, presumably dendritic cells, which constitute the predominant antigen-presenting cell population. ${ }^{33}$ Earlier studies indicated that trauma-hemorrhage is associated with significantly decreased capacities to present antigen and MHC class II expression by splenic APCs. ${ }^{9,33}$ In those studies, however, dendritic cells and macrophages were not separated. Moreover, in those studies naive APCs were investigated as opposed to cultured APCs.

\section{CONCLUSIONS}

The results of the present study extend previous findings demonstrating altered T-cell-APC interaction following trauma-hemorrhage which might be responsible for prolonged immunosuppression under those conditions. Moreover, T-cells appear to play an important role in mediating immunodysfunction following traumahemorrhage. In this regard, trauma-hemorrhaged T-cells depress cytokine responses and the expression of MHC II by APCs irrespective of whether APCs were subjected to trauma-hemorrhage or sham operation. Which T-cellderived mediator predominately contributes to this phenomenon, however, remains to be determined. Alterations in the expression of co-stimulatory molecules on APCs or T-cells are not evident. Thus, attempts to treat extended and prolonged immunodepression following trauma and blood loss should also be directed towards T-cells and their interaction with APCs.

\section{ACKNOWLEDGEMENTS}

Christian R. Walz and Siegfried Zedler contributed equally to this work.

This investigation was supported by a grant from the Deutsche Forschungsgesellschaft DFG AN 357/1-1. Part of the work was presented at the 29th Annual Conference on Shock, Broomfield, Colorado, 3-6 June 2006 and awarded with a Travel Award of the Shock Society.

\section{REFERENCES}

1. Angele MK, Chaudry IH. Surgical trauma and immunosuppression: pathophysiology and potential immunomodulatory approaches. Langenbecks Arch Surg 2005; 390: 333-341.

2. Walz CR, Zedler S, Schneider CP et al. Depressed T cell-derived IFN-gamma following trauma-hemorrhage: a potential mechanism for diminished APC responses. Langenbecks Arch Surg 2007; 392: 339-343.
3. Lenschow DJ, Walunas TL, Bluestone JA. CD28/B7 system of T cell costimulation. Annu Rev Immunol 1996; 14: 233-258.

4. Ayala A, Ertel W, Chaudry IH. Trauma-induced suppression of antigen presentation and expression of major histocompatibility class II antigen complex in leukocytes. Shock 1996; 5: 79-90.

5. Angele MK, Knoferl MW, Schwacha MG et al. Sex steroids regulate pro- and anti-inflammatory cytokine release by macrophages after trauma-hemorrhage. Am J Physiol 1999; 277: $\mathrm{C} 35-\mathrm{C} 42$.

6. Angele MK, Knoferl MW, Ayala A, Bland KI, Chaudry IH. Testosterone and estrogen differently effect Th1 and Th2 cytokine release following trauma-hemorrhage. Cytokine 2001; 16: 22-30.

7. Xu YX, Ayala A, Chaudry IH. Prolonged immunodepression after trauma and hemorrhagic shock. J Trauma 1998; 44: 335-341.

8. Ertel W, Keel M, Neidhardt R et al. Inhibition of the defense system stimulating interleukin-12 interferon-gamma pathway during critical illness. Blood 1997; 89: 1612-1620.

9. Kawasaki T, Fujimi S, Lederer JA et al. Trauma-hemorrhage induces depressed splenic dendritic cell functions in mice. J Immunol 2006; 177: 4514-4520.

10. Angele MK, Faist E. Clinical review: immunodepression in the surgical patient and increased susceptibility to infection. Crit Care 2002; 6: 298-305.

11. Angele MK, Schwacha MG, Ayala A, Chaudry IH. Effect of gender and sex hormones on immune responses following shock. Shock 2000; 14: 81-90.

12. Zellweger R, Ayala A, DeMaso CM, Chaudry IH. Traumahemorrhage causes prolonged depression in cellular immunity. Shock 1995; 4: 149-153.

13. Angele MK, Ayala A, Cioffi WG, Bland KI, Chaudry IH. Testosterone: the culprit for producing splenocyte immune depression after trauma hemorrhage. Am J Physiol 1998; 274: C1530-C1536.

14. Delon J, Stoll S, Germain RN. Imaging of T-cell interactions with antigen presenting cells in culture and in intact lymphoid tissue. Immunol Rev 2002; 189: 51-63.

15. Vendetti S, Chai JG, Dyson J, Simpson E, Lombardi G, Lechler R. Anergic $\mathrm{T}$ cells inhibit the antigen-presenting function of dendritic cells. J Immunol 2000; 165: 1175-1181.

16. Gregg EO, Denis M. The effect of macrophage activation state on antigen presenting capability as defined by helper T-cell function. Int J Immunopharmacol 1991; 13: 217-225.

17. Ayala A, Perrin MM, Wagner MA, Chaudry IH. Enhanced susceptibility to sepsis after simple hemorrhage. Depression of Fc and C3b receptor-mediated phagocytosis. Arch Surg 1990; 125: 70-74, discussion 74-75.

18. Partington KM, Jenkinson EJ, Anderson G. A novel method of cell separation based on dual parameter immunomagnetic cell selection. J Immunol Methods 1999; 223: 195-205.

19. Abraham E. T- and B-cell function and their roles in resistance to infection. New Horiz 1993; 1: 28-36.

20. Ayala A, Chung CS, Xu YX, Evans TA, Redmond KM, Chaudry IH. Increased inducible apoptosis in $\mathrm{CD}^{+} \mathrm{T}$ lymphocytes during polymicrobial sepsis is mediated by Fas ligand and not endotoxin. Immunology 1999; 97: 45-55.

21. Shelley O, Murphy T, Paterson H, Mannick JA, Lederer JA. Interaction between the innate and adaptive immune systems is required to survive sepsis and control inflammation after injury. Shock 2003; 20: 123-129.

22. Landy M, Baker PJ. Cytodynamics of the distinctive immune response produced in regional lymph nodes by Salmonella somatic polysaccharide. J Immunol 1966; 97: 670-679.

23. Berger SL. Lymphocytes as resting cells. Methods Enzymol 1975; 58: 486-494. 
24. Bryn T, Yaqub S, Mahic M, Henjum K, Aandahl EM, Tasken K. LPS-activated monocytes suppress T-cell immune responses and induce $\mathrm{FOXP}^{+} \mathrm{T}$ cells through a COX-2-PGE 2 -dependent mechanism. Int Immunol 2008; 20: 235-245.

25. Ransom J, Fischer M, Mosmann $\mathrm{T}$ et al. Interferon-gamma is produced by activated immature mouse thymocytes and inhibits the interleukin 4-induced proliferation of immature thymocytes. J Immunol 1987; 139: 4102-4108.

26. de Saint-Vis B, Fugier-Vivier I, Massacrier C et al. The cytokine profile expressed by human dendritic cells is dependent on cell subtype and mode of activation. J Immunol 1998; 160: 1666-1676.

27. Ayala A, Deol ZK, Lehman DL, Herdon CD, Chaudry IH. Polymicrobial sepsis but not low-dose endotoxin infusion causes decreased splenocyte IL-2/IFN-gamma release while increasing IL-4/IL-10 production. J Surg Res 1994; 56: 579-585.

28. Schinkel C. The role of IFN-gamma in surgical patients. J Interferon Cytokine Res 2003; 23: 341-349.

29. Asthana D, Yang WC, Fuller L et al. Differential effects of IFNgamma on kidney cell expression of MHC class II molecules, kidney cell associated molecules and their stimulatory capacity in mixed lymphocyte kidney cell culture. Transpl Immunol 1993; 1: 282-293.

30. Granucci F, Zanoni I, Feau S, Ricciardi-Castagnoli P. Dendritic cell regulation of immune responses: a new role for interleukin
2 at the intersection of innate and adaptive immunity. EMBO $J$ 2003; 22: 2546-2551.

31. De AK, Laudanski K, Miller-Graziano CL. Failure of monocytes of trauma patients to convert to immature dendritic cells is related to preferential macrophage-colony-stimulating factordriven macrophage differentiation. J Immunol 2003; 170: 6355-6362.

32. Banchereau J, Steinman RM. Dendritic cells and the control of immunity. Nature 1998; 392: 245-252.

33. Schneider CP, Schwacha MG, Chaudry IH. Influence of gender and age on T-cell responses in a murine model of traumahemorrhage: differences between circulating and tissue-fixed cells. J Appl Physiol 2006; 100: 826-833.

34. Oberbeck R, Nickel E, von Griensven $M$ et al. The effect of dehydroepiandrosterone on hemorrhage-induced suppression of cellular immune function. Intensive Care Med 2002; 28: 963-968.

35. Sun ZW, Qiu YH, Shi YJ et al. Time courses of B7 family molecules expressed on activated T-cells and their biological significance. Cell Immunol 2005; 236: 146-153.

36. Turina M, Dickinson A, Gardner S, Polk Jr HC. Monocyte HLA-DR and interferon-gamma treatment in severely injured patients - a critical reappraisal more than a decade later. J Am Coll Surg 2006; 203: 73-81. 